\title{
Spatial distribution of conductances and currents associated with a north-south auroral form during a multiple-substorm period
}

\author{
O. Amm ${ }^{1}$, A. Pajunpää ${ }^{1}$, U. Brandström ${ }^{2}$ \\ ${ }^{1}$ Finnish Meteorological Institute, Geophysical Research Division, PO Box 503, FIN-00101 Helsinki, Finland \\ ${ }^{2}$ Swedish Institute of Space Physics, PO Box 812, S-98128 Kiruna, Sweden
}

Received: 13 April 1999 / Revised: 2 July 1999 / Accepted: 5 July 1999

\begin{abstract}
Using the method of characteristics to invert ground-based data of the ground magnetic field disturbance and of the ionospheric electric field, we obtain spatial distributions of ionospheric conductances, currents, and field-aligned currents (FACs) associated with a north-south auroral form that drifts westwards over northern Scandinavia around 2200 UT on December 2, 1977. This auroral form is one in a sequence of such north-south structures observed by all-sky cameras, and appears 14 min after the last of several breakups during that extremely disturbed night. Our analysis shows that the ionospheric Hall conductance reaches values above $200 \mathrm{~S}$ in the center of the form, and upward flowing FACs of up to $25 \mu \mathrm{A} / \mathrm{m}^{2}$ are concentrated near its westward and equatorward edge. The strong upward flowing FACs are fed by an area of more distributed, but still very strong downward-flowing FACs northeastward of the auroral form. In contrast to the conductances, the electric field is only slightly affected by the passage of the form. We point out similarities and differences of our observations and results to previously reported observations and models of 'auroral fingers', 'north-south aurora', and 'auroral streamers' which are suggested to be ionospheric manifestations of bursty bulk flows in the plasma sheet.
\end{abstract}

Key words. Ionosphere (auroral ionosphere; electric fields and currents) $\cdot$ Magnetospheric physics (magnetosphere - ionosphere interactions)

\section{Introduction}

A number of studies has been carried out to investigate the relation between auroral forms and ionospheric electrodynamic quantities, such as conductances, currents, and field-aligned currents (FACs) during substorms. They can be ordered into two groups: one of them makes use of simultaneous observations from loworbiting satellites to detect the magnetic field effect of FACs, and of either ground-based all-sky cameras or high orbiting satellites that provide global auroral images (e.g., Bythrow and Potemra, 1987; Lopez et al., 1991; Hoffman et al., 1994). The other focuses on combining the auroral images with ground-based data from magnetometers, radars, and other instruments if available (e.g., Robinson et al., 1985, Kamide et al., 1989; Untiedt and Baumjohann, 1993, and references therein), while other satellite data may be used as supplementary evidence.

A shortcoming of satellite-based studies is that to obtain a spatial picture, many different passes, often from different days, have to be combined. Therefore, the results are mainly of a statistical nature, as in the classical study of Ijima and Potemra (1978) of the FAC distribution during substorms. Fujii et al. (1994) and Hoffman et al. (1994) have binned a large data set of satellite passes according to several sectors of the substorm aurora, and scaled the passes from different days with respect to the intensity of each substorm to construct a combined pattern of FACs and ionospheric currents for the whole substorm area. Despite their very careful data treatment, it is still not clear if their combined result could represent a single event, and it is difficult to link their results to individual, instantaneously observed auroral forms. Moreover, since no information on conductances and the electric field was available, the estimation of ionospheric currents from FACs contains considerable uncertainty. Another problem in obtaining FAC densities from magnetic field measurements along satellite passes is that for a proper quantitative analysis, the assumption that the FAC configuration is that a (practically) infinite current sheet has to be made.

During and after the International Magnetospheric Study (IMS, 1976-1979), several studies were carried out that combined ground magnetic field data from the arrays set up during this period with ionospheric electric field data measured by coherent scatter radars (e.g., 
Akasofu et al., 1980; Kamide et al., 1982; see the review of Untiedt and Baumjohann, 1993, for the studies carried out with observations from Scandinavia). Many of these works addressed the spatial conductance, electric field, currents, and FAC distribution associated with auroral forms, such as the westward traveling surge (WTS; e.g., Inhester et al., 1981; Opgenoorth et al., 1983a), the auroral breakup (e.g., Opgenoorth et al., 1980; Baumjohann et al., 1981), or omega bands (e.g., André and Baumjohann, 1982; Opgenoorth et al., 1983b). The method of analysis used in these studies was the 'trial and error' method, i.e., the searched ionospheric parameters were modeled until a sufficient fit between the measured quantities and their values as calculated by the models was obtained. While these studies are still standard references, later works, particularly those including data from incoherent scatter radars, have shown that their method of analysis has introduced considerable smoothing of the resulting features (compare, for the WTS case, e.g., Kirkwood et al., 1988; Aikio and Kaila, 1996). One reason for this is that 'trial and error' method typically starts out with rather uniform ionospheric distributions, and gradients are only gradually introduced if they are unavoidable to obtain a fit of the measured ground magnetic field disturbance that matches a given relative error. However, due to the integrating effect of the ground magnetic field disturbance, there is also a general resolution boundary of about $100 \mathrm{~km}$ wavelength for studies that utilize ground magnetometers.

A considerable improvement in the analysis approach of ground-based data was introduced with the 'method of characteristics' (Inhester et al., 1992; Amm, 1995, 1998). In contrast to the 'trial and error' approach, this method is a forward technique in which a 2D partial differential equation is solved along its characteristics for the Hall conductance as the primary output. Together with the measurements and an estimate of Hall to Pedersen conductance ratio, spatial distributions of the remaining electrodynamic parameters are inferred. The method of characteristics has been shown to provide substantially more detailed results than the "trial and error' method, and it is, in particular, more suited to resolve inhomogeneous ionospheric situations (Amm, 1995, 1998). Moreover, the number of assumptions needed is reduced compare to the 'trial and error' method, for which both the Hall and Pedersen conductance have to be assumed independently. In contrast to the individual conductances, their ratio has been shown to be relatively stable and assessable from the level of ground magnetic activity (see Schlegel, 1988; Lester et al., 1996). In addition, Amm (1995) has shown the influence of the estimate of that ratio on the final results of the method of characteristics to be small.

We analyze a north-south auroral structure that appeared on December 2, 1977, over northern Scandinavia as one in a sequence of such north-south auroral forms. The form first appeared at $2155 \mathrm{UT}, 14 \mathrm{~min}$ after the last of several auroral breakups during the extremely disturbed night, and drifted westward with a speed of about $1.4 \mathrm{~km} / \mathrm{s}$. We use the method of characteristics to infer spatial distributions of conductances, ionospheric horizontal and field-aligned currents for the time step at 2200 UT, when the backscatter of the coherent scatter radar STARE is sufficient to provide electric field data over nearly its complete field-of-view, and compare our results with the auroral display. We also show how the specific ground magnetic signature of the form is produced.

Not many studies are available in the literature about north-south auroral forms. Rostoker et al. (1987) have described such north-south structures which they call 'auroral fingers' viewed by the Viking satellite imager. They found these forms to be a facet of the auroral oval when it has a north-south width of more than $10^{\circ}$ of latitude, which only happened during very strong substorms, and at least $10 \mathrm{~min}$ after the substorm onset. The north-south extent of their structures is about $450 \mathrm{~km}$, and multiple forms with a longitudinal separation of $150-300 \mathrm{~km}$ occurred. They attributed these forms to traces of drift paths of high energetic electron populations which have been injected along the velocity shear zone separating the central plasma sheet (CPS) from the low latitude boundary layer (LLBL) during the substorm expansive phase, and subsequently drift Earthward. During that drift, the electrons experience Fermi and betatron acceleration, so that the equatormost edge of the north-south auroral form should be associated with the most energetic electrons.

This scenario has been refined and supported with quantitative considerations by Liu and Rostoker (1993). They suggest the Kelvin-Helmholtz instability to be the mechanism to inject cold plasma from the LLBL into the CPS. The charge separation that such a cold plasma blob undergoes due to adiabatic drift is compensated by a pair of one upward- and one downward-flowing FAC in their model. They expect electrons with energy upward to $10 \mathrm{keV}$ to be precipitating to the ionosphere in the upward FAC region.

In their comprehensive substorm aurora study, Nakamura et al. (1993) have identified north-south auroral structures (they call 'N-S aurora') in the central auroral bulge just east of the surge. They also found multiple, longitudinally separated north-south auroral forms that drifted westwards and expanded equatorwards. Consistent with the observations of Rostoker et al. (1987) and Liu and Rostoker (1993), the westernmost of their N-S aurora forms showed a hook-like tilt to the west, whereas the easternmost ones show such a tilt towards the east. In later substorm phases, the N-S aurora develops to diffuse or pulsating aurora. Nakamura et al. (1993) explain their events in terms of a local two-cell potential at the auroral bulge, where the negative charges located in the surge and the positive ones at the northernmost arc of the auroral bulge east of the surge. The auroral evolution is then explained as traces of rapid plasma flows in the local two-cell potential.

Recently, several works have related north-south auroral forms, partly called 'auroral streamers', to bursty bulk flows (BBF) in the central plasma sheet (Sergeev et al., 1996, 1999; Angelopoulos et al., 1997; 
Henderson et al., 1998) which were explained by Chen and Wolf (1993) as rapidly Earthward convecting plasma bubbles with lower particle, but higher magnetic pressure than the surrounding plasma. These auroral streamers are localized auroral activations that expand equatorward from the poleward boundary of the aurora to form north-south structures, often during the expansion phase of a substorm (Elphinstone et al., 1996). They are therefore quite similar to the N-S aurora described by Nakamura et al. (1993). Chen and Wolf (1993) predicted the ionospheric current signature of the BBF to be a very localized current wedge, with the downward FACs on the eastern and the upward FACs on the western side of it.

None of the previous studies presents a self-consistent model of ionospheric currents, conductances, and FACs associated with the auroral events. We will discuss our results for these quantities in the context of the studies mentioned.

\section{Instrumentation}

For our analysis, ground magnetic data of the Scandinavian Magnetometer Array (SMA; Küppers et al., 1979) is used (Fig. 1), which is still the most extensive magnetometer array ever set up in northern Scandinavia. Except for the six magnetometers of the chain KUU to SKA which are of a digital fluxgate type, the instruments are of a modified version of the classical Gough-Reitzel type.

Ionospheric electric field data is provided by the STARE coherent scatter radar (Greenwald et al.,

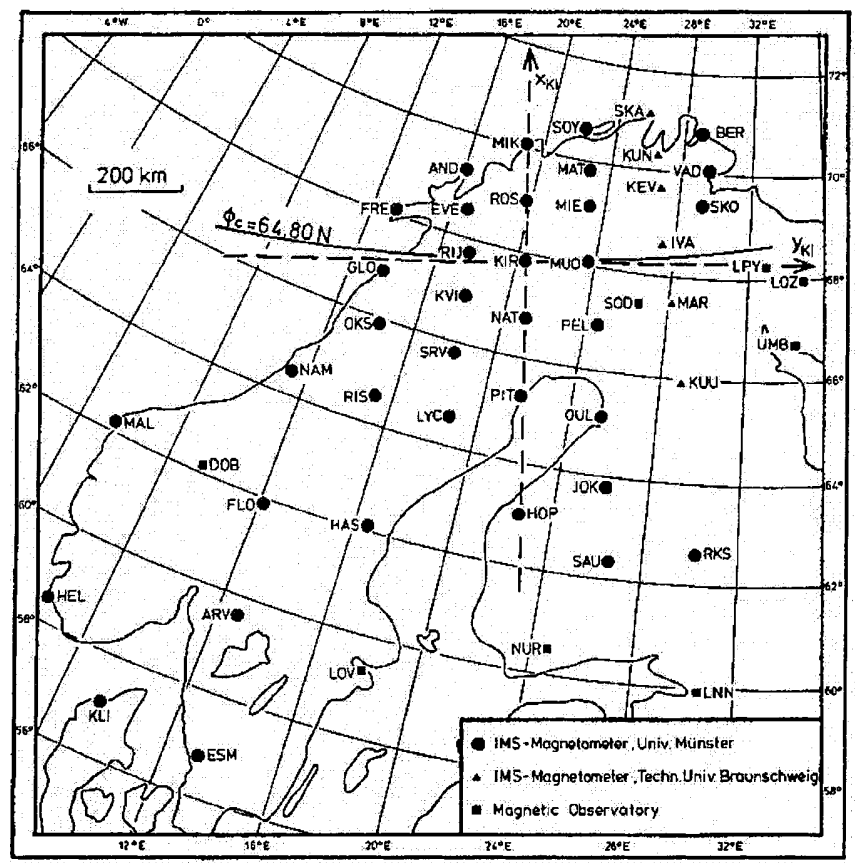

Fig. 1. Magnetometer stations of the Scandinavian Magnetometer Array (SMA); solid lines: geographical coordinates; the broken lines mark a local cartesian coordinate system that is not used in this work; from Küppers et al. (1979)
1978). In the area of overlapping radar beams of the two radar stations (Fig. 2), vector information of the ionospheric electric field can be composed from the electron drift velocities along the beam directions measured by the individual radar stations, provided that both of them receive sufficient backscatter. As one of several conditions, backscatter is regularly observed if the line-of-sight (i.e., along the beam directions) electron velocity exceeds about $360 \mathrm{~m} / \mathrm{s}$ which corresponds to a electric field magnitude perpendicular to the beam of about $18 \mathrm{mV} / \mathrm{m}$ (e.g., Haldoupis et al., 1990). However, occasionally backscatter can also be received for line-of-sight electron velocities down to about $200 \mathrm{mV} / \mathrm{m}$.

All sky camera (ASC) data was used for this study from the stations in Kiruna, Muonio, and Ivalo (see KIR, MUO, and IVA in Fig. 1). However, because of partial cloudiness, not all pictures of these station could be used during the period of interest.

\section{Data description and analysis}

The day of December 2, 1977, was characterized by a long-lasting and extremely strong auroral and ground magnetic activity. The $K p$ index took the high value of 7 from 15-24 UT, and ground magnetic disturbances of the order of $1000 \mathrm{nT}$ and more were observed. At 1630 UT, the Harang discontinuity event studied by Kunkel et al. (1986) took place. This early appearance of the Harang discontinuity points to a equatorward

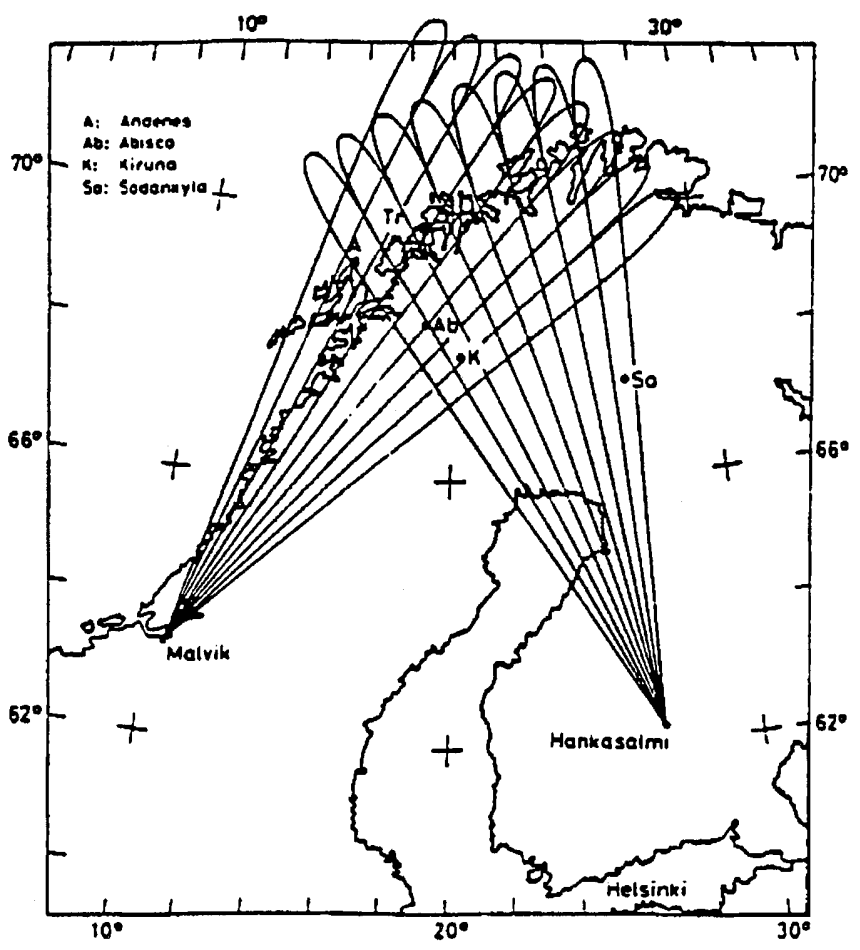

Fig. 2. Map of the two STARE radar stations and schematic representation of their radar beams. The area of overlapping beams corresponds to the field of view of the radar in which vector electric field data can be measured; from Greenwald et al. (1978) 
displacement of the ionospheric current systems connected with an expansion of the auroral oval that is often observed during strongly disturbed periods.

The event studied here started at 2155 UT, $14 \mathrm{~min}$ after one of several auroral breakups observed during that night and a corresponding renewed intensification of the ground magnetic disturbance, when a north-south (N-S) auroral form showed up over the zenith at Muonio, i.e., at the eastern edge of the STARE field of view (compare Fig. 2). This form moved westwards with a velocity of about $1.4 \mathrm{~km} / \mathrm{s}$, and disappeared from the western horizon of the all sky cameras and from the western edge of the STARE field of view at 2207 UT. Since the pictures of the cameras at Muonio and Kiruna were partly disturbed by clouds, in Fig. 3 we show an undisturbed example of such a north-south aurora from Ivalo (east of the STARE field-of-view) at 2201 UT, which is taken from the next one in the sequence of westward-moving north-south auroral forms during the period of interest.

While the initial development of the N-S auroral form under study cannot be followed in detail in the Muonio ASC data because of the clouds, an initial equatorward expansion is seen near the western horizon from the camera at Ivalo. Since the equatorward edge of the auroral form in associated with a minimum of the $\mathrm{Z}$ (vertical, positive downward) component of the ground magnetic disturbance as will be shown below, an estimate of the equatorward speed of this initial expansion can be obtained from the $\mathrm{Z}$ magnetograms of the north-south chain MAT-PEL (Fig. 4a; SOY and OUL did not measure $\mathrm{Z}$ components). As indicated by the black arrows in Fig. 4a, minimum of the $\mathrm{Z}$ moves equatorward around 2155 UT with a velocity of about $2.4 \mathrm{~km} / \mathrm{s}$. Figure $4 \mathrm{~b}$ shows a distinct "sawtooth-like" appearance of the N-S auroral form in the Y (eastward) ground magnetic disturbance component. The arrows in

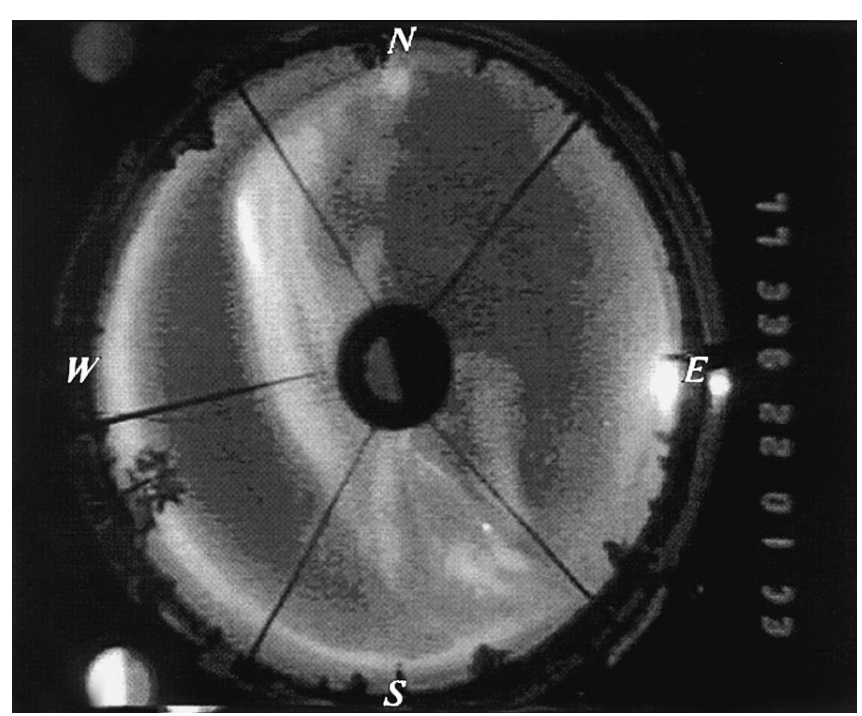

Fig. 3. Typical example of a north-south aligned auroral form observed in the night of December 2, 1977; picture of the all-sky camera at Ivalo, $2201 \mathrm{UT}$ (geographic north points to the top, east to the right)
Fig. $4 \mathrm{~b}$ show the westward movement of the zero crossings of the $\mathrm{Y}$ component from positive to negative after 2155 UT. The location of these zero crossings approximately, but not exactly, corresponds to the longitudinal center of the auroral form (see the detailed analysis).

In our single time step analysis, we focus of the instant at 2200 UT when the auroral form under study is in the western part of STARE field-of-view, because then the radar receives backscatter in nearly its whole measurement area, whereas earlier when the form was more in the center of the STARE area there were considerable holes in the electric field vector data.

In the period between the breakup and our event, the horizontal ground magnetic disturbance $\vec{B}_{G, h}$ in the SMA array was dominated by a relatively uniform, at $500 \mathrm{nT}$ already quite strong, westward electrojet. About between 2155 and 2207 UT a short disturbance occurs which is characterized at its climax at 2200 UT by three signatures (Fig. 5a): first, a clear intensification of the westward electroject can be seen, particularly between 67 and $69^{\circ}$ of latitude and 18 to $24^{\circ}$ of longitude, with a magnitude of the horizontal disturbance of about $720 \mathrm{nT}$. Second, about between 20 and $25^{\circ}$ of longitude, a distinct northward deviation of the by $90^{\circ}$ rotated ground magnetic disturbance is observed. Finally, in the western part of the SMA area at the southern border of the westward electrojet, a curl-like structure is visible, the center of which can roughly be estimated at $63^{\circ}$ of latitude and $18^{\circ}$ of longitude. Like the auroral form, these magnetic signatures are traveling westwards with a speed of about $1.4 \mathrm{~km} / \mathrm{s}$. Although the signatures as such remain stable during our event, the ground magnetic disturbance $\vec{B}_{G}$ is far from being stationary. After about 2207 UT, the magnetic disturbance decreases, and the discrete aurora fades or evolves into diffuse aurora.

Compared to the ground magnetic disturbance, the electric field $\vec{E}$ as measured by the STARE radar is much less structured (Fig. 5b). Except for local small-scale inhomogenities, it shows mainly southwestward-directed vectors east of 20 degrees of longitude, and mainly southward-directed ones west of this. The magnitude of $\vec{E}$ is around $20 \mathrm{mV} / \mathrm{m}$, with little variability. This general picture of $\vec{E}$ shows little difference to the one observed a few minutes earlier to later, except for regions of missing backscatter before the time step analyzed here. However, also during instances of missing backscatter, the remaining vectors show the same features as described. No westward motion is visible in the electric field data. From these observations alone it can already be presumed that the main effect of the ground magnetic disturbance must originate in the ionospheric conductances.

Figure $5 \mathrm{c}$ shows the north-south auroral form under study in the western part of the field of view of the ASC camera at Muonio. The bright north-south aligned discrete arc shows a crescent shape towards the east at its southernmost edge. Note that the dark spots at the western horizon are clouds, and also around the zenith some thin clouds disturb the picture. Eastward of the 


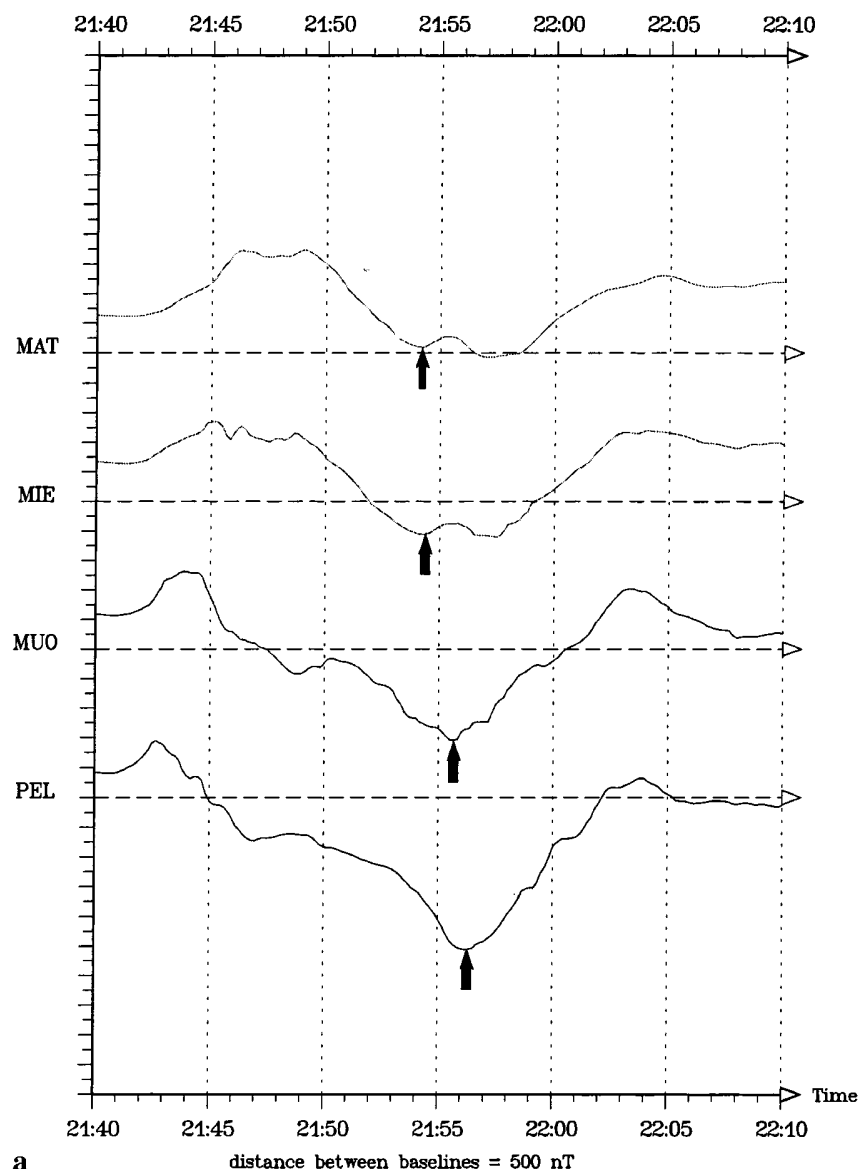

Fig. 4a, b. Magnetograms of two selected chains from the SMA array. a Vertical (Z, positive-downward) component from a northsouth chain from SOY to OUL; the increasing and equatorward moving minimum around 2155 UT corresponds to the initial development of the N-S auroral form studied. b Eastward (Y)

bright arc, an area with diffuse aurora can be seen, with decreasing intensity towards the east. The longitudinal location of the center of the bright aurora is estimated to about $16 \pm 0.5^{\circ}$, supported from the ASC camera at Kiruna (data not shown here, since the general pattern is the same as seen from Muonio, but Muonio has a slightly better image quality). Although the mapping of auroral forms ASC pictures to geographical locations exhibits some uncertainties if the forms are far from the zenith, we feel sufficiently sure about our estimate since it is confirmed by the movement of the magnetic signatures that show an analogous spatial development to the auroral forms. At the eastern horizon, another north-south aligned aurora is seen that probably belongs to the subsequent north-south aligned aurora as shown in Fig. 3.

Figure 6a shows the resulting Hall conductance $\Sigma_{H}$ obtained using the method of characteristics. We note that this method gives an upper and lower estimate for $\Sigma_{H}$ in areas where the solution is not unique. This may happen because for relatively small analysis areas and small values of $|\operatorname{div} \vec{E}|$, as in the case of our study, the boundary values for solving the differential equation for $\Sigma_{H}$ along the individual characteristics may still have

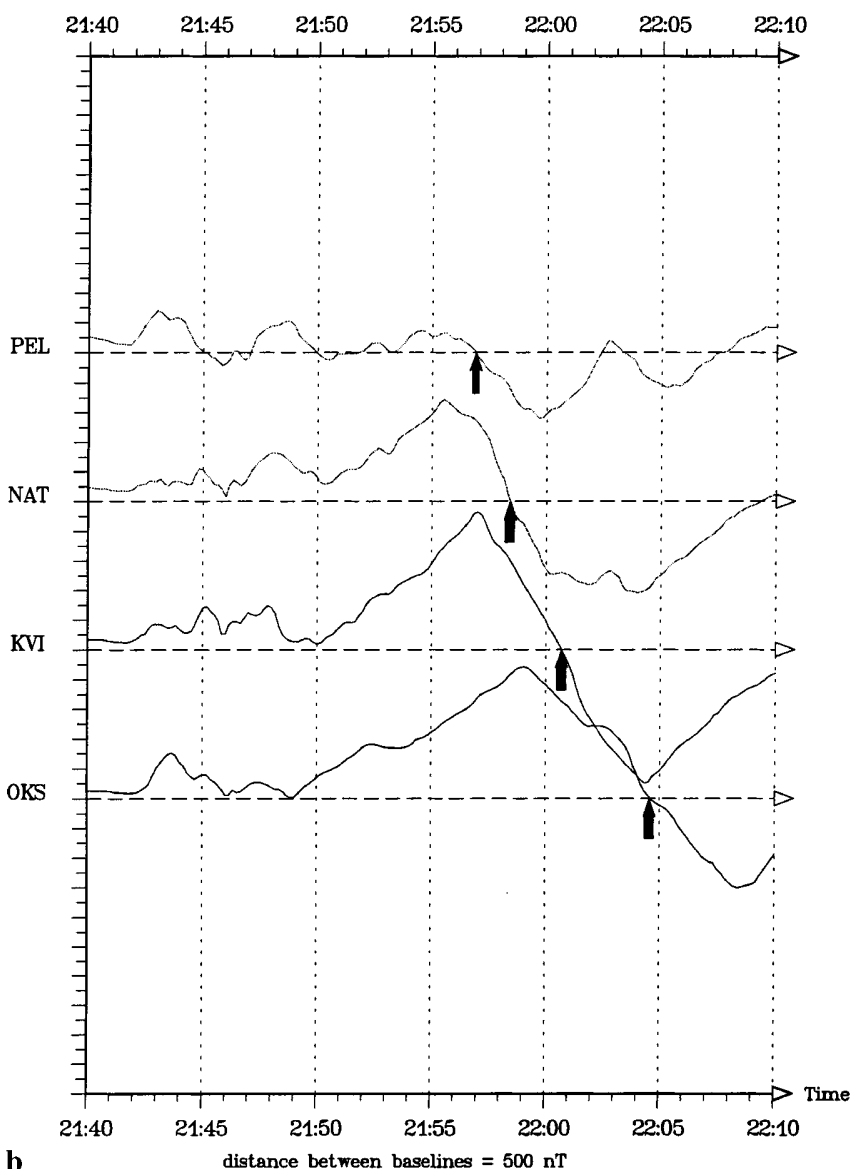

component from a east-west chain from PEL to OKS; after 2155 UT, a characteristic "sawtooth-like" structure in $\mathrm{Y}$ is seen. The $\mathrm{Y}=0$ crossing approximately corresponds to the center of the N-S auroral form which moves westward over the SMA array

some influence on the solution. However, typically this influence is decreasing exponentially with the path length of each characteristic from the boundary (compare Amm, 1998, for details). It is important to understand that this uncertainty is not caused by the special method of solving for $\Sigma_{H}$, but by the physical setup of solving the ionospheric electrodynamic equations inside a bounded domain of space. In the case of Fig. 6a, the difference between the upper and lower values for $\Sigma_{H}$ is everywhere marginal except for the region east of $24^{\circ}$ of longitude, and for the local increase in $\Sigma_{H}$ at the southern boundary between 22 and $24^{\circ}$ of longitude. These regions are therefore excluded from the following analysis. Since all ionospheric distributions are dominated by the features associated with the auroral form in the west, this is not a significant drawback. In areas of non-unique solution for $\Sigma_{H}$, the medium between the upper and lower estimates is displayed in Fig. 6a.

The most striking feature of Fig. 6a is a strip of strongly enhanced Hall conductance centered at about $16^{\circ}$ longitude, with a maximum of $225 \mathrm{~S}$ at $69^{\circ}$ latitude. This strip is well colocated with the discrete part of the north-south auroral form (see Fig. 5c). Hall conduc- 

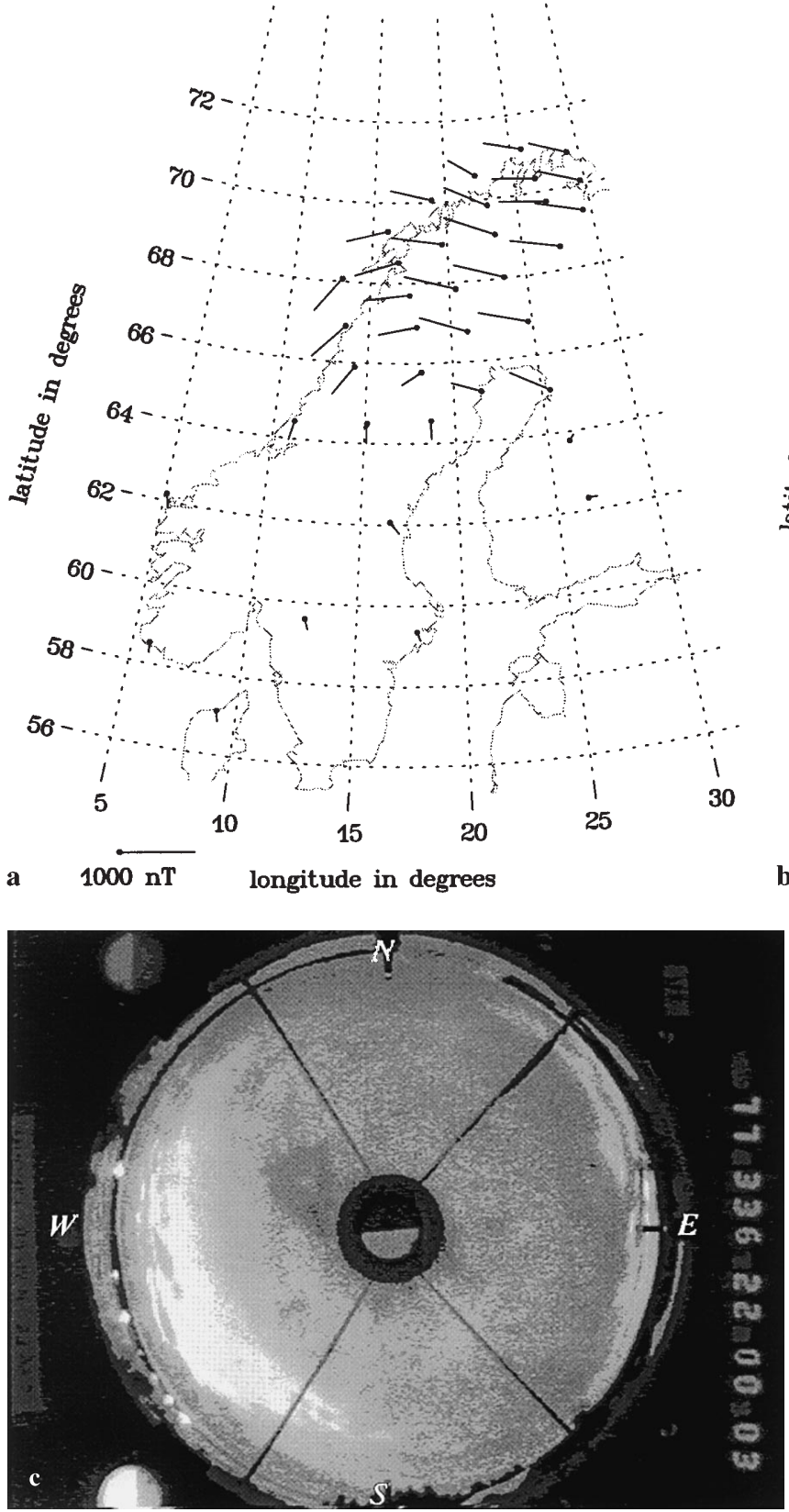

tances in that range are not often found in the literature, but on the other hand they are not uncommon in incoherent scatter radar measurements. Aikio and Kaila (1996) observed $\Sigma_{H}$ values above $200 \mathrm{~S}$ with the EISCAT radar near an intense auroral form during the expansion phase of a substorm. Such high Hall conductances are believed to be caused by high energetic electrons precipitating into the ionosphere within the auroral structure. Northward and southward of the maximum, $\Sigma_{H}$ takes values around $140 \mathrm{~S}$ in the strip which seems to show a slight tilt in northwest-southeast direction. At the southern boundary of the area under study, it drops to values around $50 \mathrm{~S}$. To the east of the strip, $\Sigma_{H}$ decreases gradually until it reaches about $30 \mathrm{~S}$ at $23^{\circ}$ longitude. This behavior agrees well with the gradual decrease in intensity of the diffuse aurora

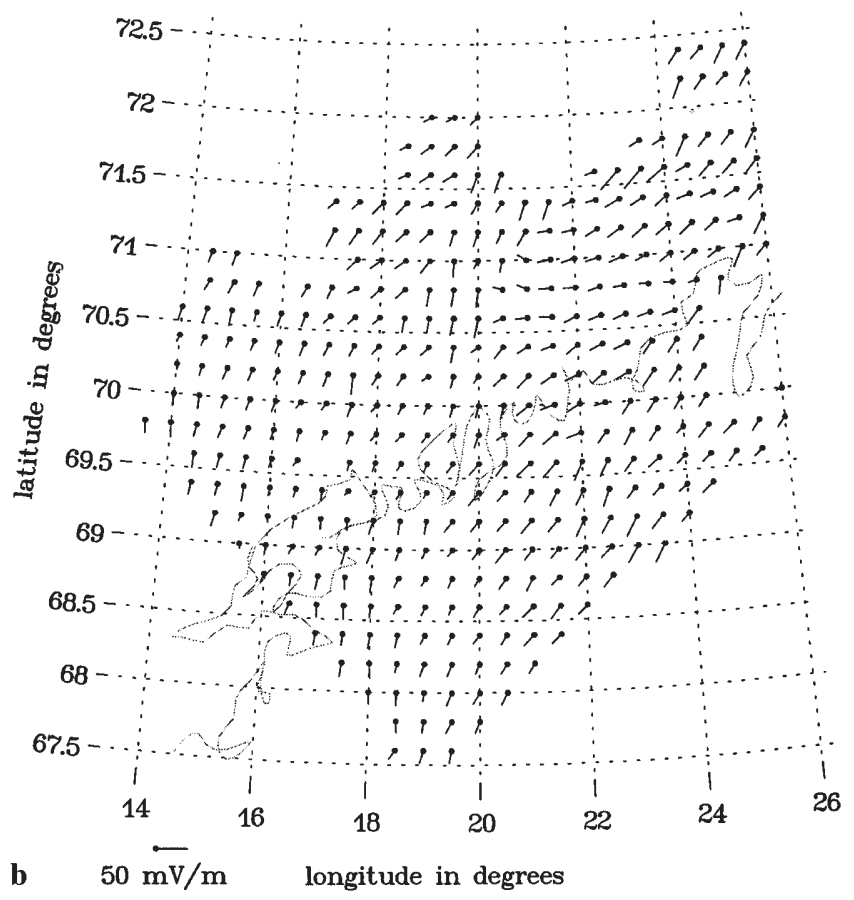

Fig. 5a-c. Measurements used in the single time step analysis of the north-south auroral form on December 2, 1977, at 2200 UT. a By $90^{\circ}$ clockwise rotated horizontal ground magnetic field disturbance, observed by the SMA. b Electric field vectors observed by the STARE radar. c All sky camera picture from Muonio, with the analyzed north-south auroral form in the western (left) part (picture modified for enhanced contrast); the north-south aurora at the eastern horizon is probably related to the subsequent form as shown in Fig. 3; note some clouds at the western horizon as well as thin clouds near the zenith (geographic north points to the top, east to the right)

located eastward of the discrete north-south auroral form seen in Fig. 5c.

The resulting ionospheric currents $\vec{J}$ (Fig. 6b) show magnitudes near $2500 \mathrm{~mA} / \mathrm{m}$ in the area of enhanced conductance, reaching even values above $3500 \mathrm{~mA} / \mathrm{m}$ at the $\Sigma_{H}$ maximum. $\vec{J}$ points nearly purely westward in the northern part of the strip of enhanced conductance, whereas in its southern part and southwest of it, $\vec{J}$ shows a substantial southward component. Eastward of the auroral form and the enhanced conductance strip, $|\vec{J}|$ decreases to about $1000 \mathrm{~mA} / \mathrm{m}$, and the direction of the currents is mainly westwards, except for a region around $71^{\circ}$ latitude and $22^{\circ}$ longitude where $\vec{E}$ locally deviates to the west, and therefore $\vec{J}$ deviates to the north. Note that the clear northward deflection of the by $90^{\circ}$ clockwise rotated $\vec{B}_{G, h}$ eastward of the auroral form is 


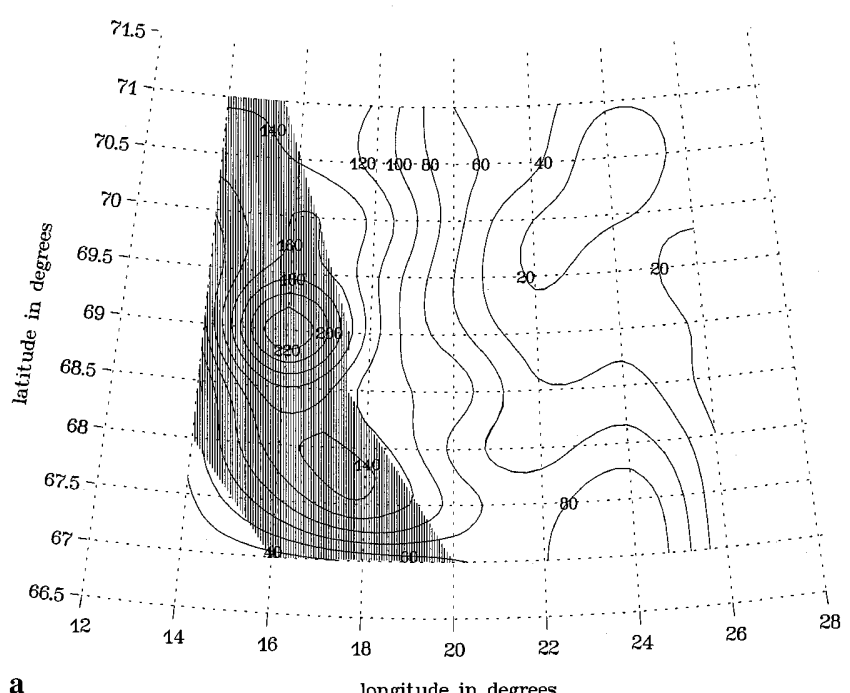

a

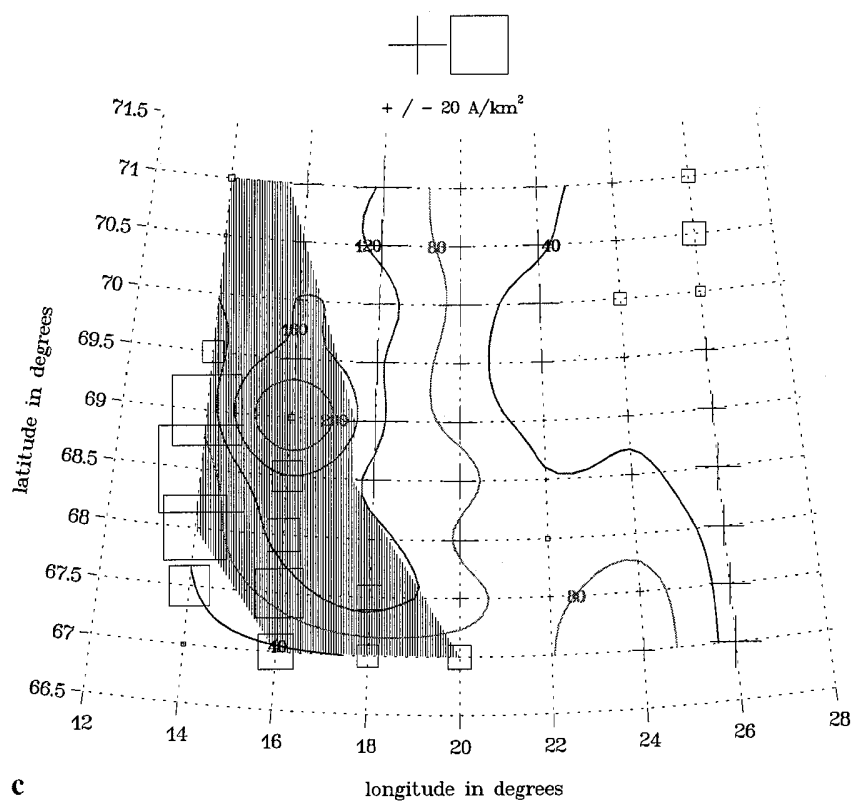

not visible, and their southward deflection at the western boundary of the analysis area is much less visible in $\vec{J}$.

The structure of the FACs (Fig. 6c) is also completely dominated by the conductance enhancement in the area of the discrete auroral form: north of $68^{\circ}$ latitude, eastward of the enhanced $\Sigma_{H}$ strip, a north-south aligned sheet of downward flowing FACs with amplitudes around $15 \mathrm{~A} / \mathrm{km}^{2}$ is visible that slightly widens towards the north. These already very strong FACs are still surpassed by the upward flowing FACs in the southern and western part of the analysis area which form a northwest-southeast aligned layer and reach amplitudes up to about $25 \mathrm{~A} / \mathrm{km}^{2}$. This upward FAC layer closely follows the shape of the westward side of the equatorward edge of the north-south auroral form (compare Fig. 5c). It is also interesting to observe that this FAC layer seems to be roughly colocated with the brightest part of the north-south aurora at its western flank. It is likely that the upward FAC sheet continues westwards of the analysis area towards the northwest,

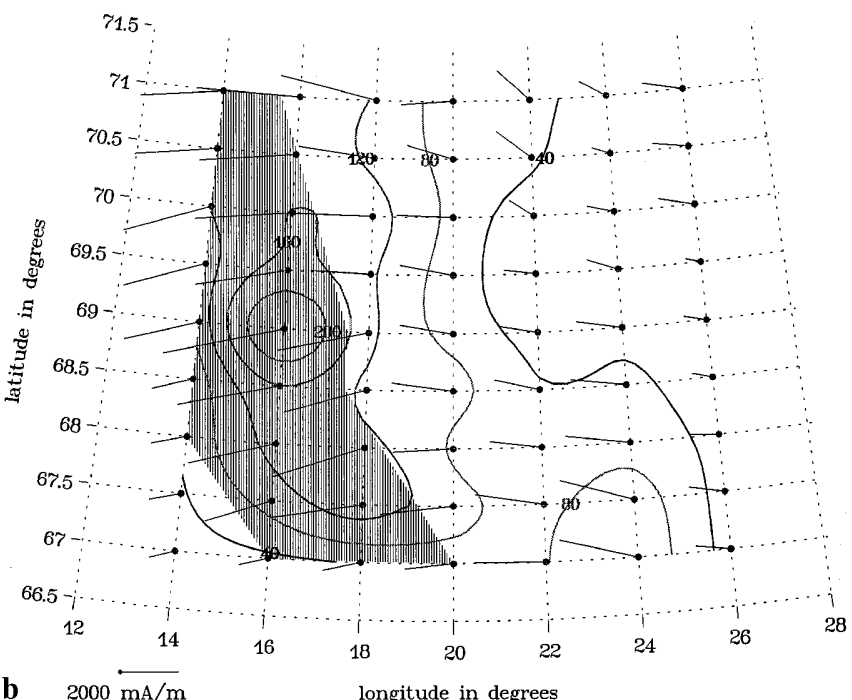

Fig. 6a-c. Results obtained with the method of characteristics from the input data as shown in Fig. 5a, b. a Hall conductance in S. b Horizontal ionospheric currents, with some Hall conductance iso contours. c Field-aligned current density (positive-downwards), with some Hall conductance iso contours. The shaded areas correspond to the estimated geographical location of the discrete N-S aurora

since the decrease of $\Sigma_{H}$ to the west is not fully contained in our analysis region. The FACs at the eastern boundary in Fig. 6c are located in the area of badly determined conductances and are likely to be artificial. The cross-structure size of the FAC current system can roughly be estimated to $6^{\circ}$ longitude or $250 \mathrm{~km}$ on the ionospheric height. Note that, as can be shown by an order-of-magnitude calculation, for the FAC densities obtained still many fewer charge carriers are required to carry the current than are available in the auroral ionosphere (e.g., Kirkwood et al., 1988; Robinson and Vondrak, 1990).

As a check of our analysis results, we recalculated the ground magnetic disturbance that follows from the horizontal ionospheric currents and from the FAC as shown in Fig. 6b, c and compared it with the measured ground magnetic disturbance. Since the magnetic field of a line current decreases as the inverse of the distance from the axis of current flow, one normally cannot expect to obtain the complete ground magnetic distur- 

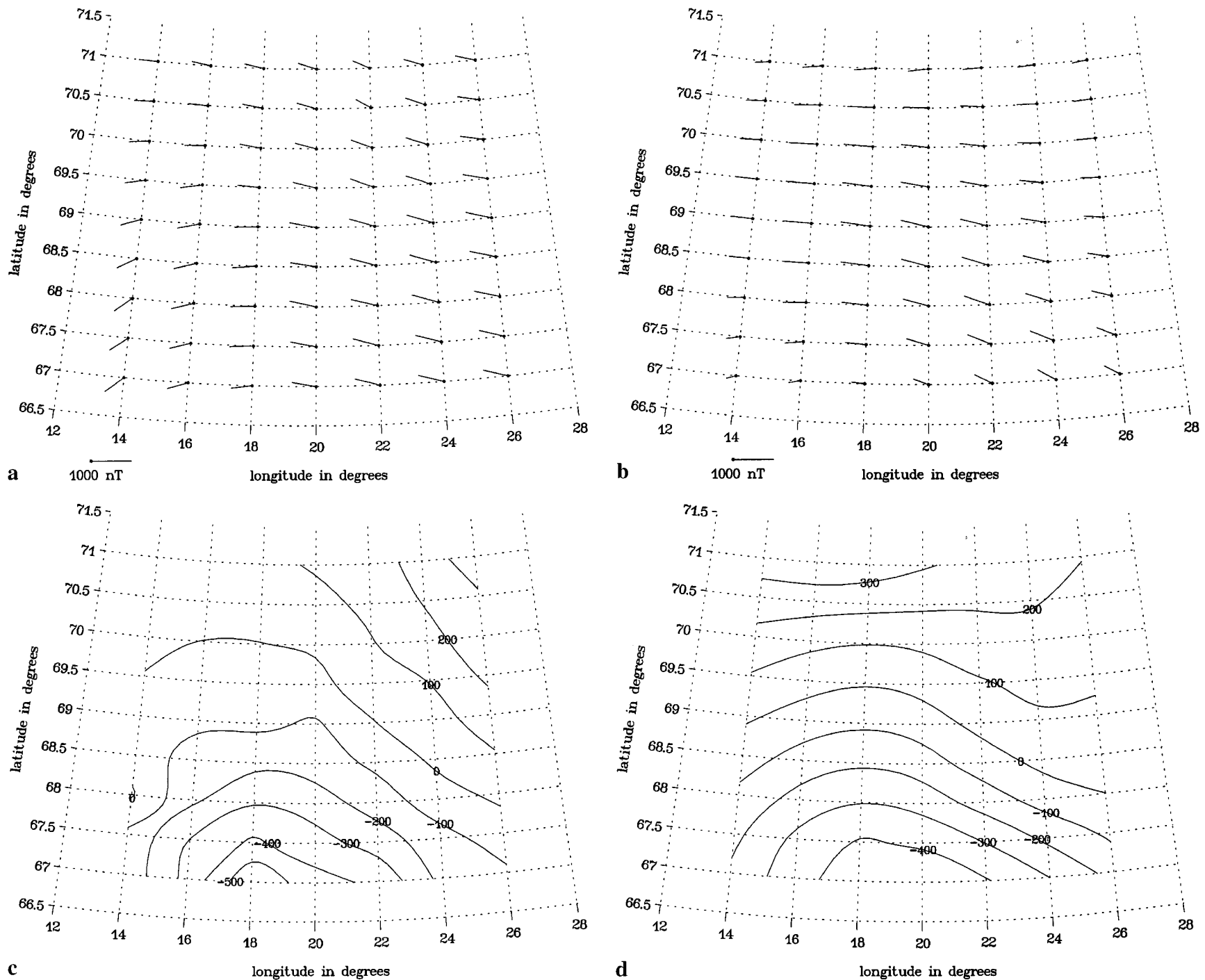

Fig. 7a-d. Comparison of measured ground magnetic field disturbance interpolated on a grid with the ground magnetic disturbance as recalculated from the three-dimensional current system resulting from our analysis (Fig. 6b, c). a Measured by $90^{\circ}$ clockwise rotated

bance in a certain domain from the currents and FACs that flow overhead that same domain only. However, in our special case the large conductance enhancement that is confined in our analysis region leads to the conjecture that here most of the ground magnetic effect might be caused inside the analysis region itself. Then it should be possible to reconstruct, at least, the essential structure of the ground magnetic disturbance from our results.

Figure 7 shows the measured and the recalculated by $90^{\circ}$ rotated horizontal ground magnetic disturbance as well as the vertical magnetic disturbance (positive downwards). The former is interpolated on the same grid as the analysis results. For the by $90^{\circ}$ rotated horizontal disturbance (Fig. 7a, b), a very good general agreement between the two distributions is seen, especially in the center of the analysis region. In particular, the northward deviation of the vectors between 20 and $22^{\circ}$ longitude is well represented. Also the curl-like

horizontal disturbance. b Recalculated by $90^{\circ}$ clockwise rotated horizontal disturbance. c Measured vertical disturbance (positivedownwards). d Recalculated vertical disturbance

structure in the southwest is present, although it is weaker in the recalculated field than in the measured one, probably mostly because of missing upward flowing FACs beyond the western border of our analysis region. Similarly, the difference between the northward deviated measured vectors at the northern boundary and slightly southward deflected vectors in the recalculated field can be explained by missing downward flowing FACs north of that boundary. It is interesting to note that the quite inhomogeneous distributions of $\vec{J}$ and $j_{\|}$in Fig. $6 \mathrm{~b}$, c are able to reproduce the somewhat smoother ground magnetic disturbance distributions.

Also regarding the vertical component of the ground magnetic disturbance (Fig 7c, d), we obtain a generally good correspondence between the measured and the recalculated field, especially in the central and southern part of the analysis area. Near the western part of the northern boundary, however, the recalculation yields a clearly higher vertical disturbance than was measured. It 
is very likely that this difference is caused by missing strong westward-flowing currents that flow northwestward of the analysis region in the continuation of the strip of enhanced conductances and discrete aurora. They would cause a negative vertical disturbance in the northwestern analysis region whereas the horizontal magnetic disturbance component inside this region would be less affected. The fact that a similar effect is not visible at the southern boundary suggests that the real ionospheric currents south of the region under study are weak.

To summarize the recalculation of the ground magnetic disturbance, we can say that the agreement of the recalculated and the measured disturbance is at least as good as for a typical 'trial and error' study. The reason why the latter method never yields such strong gradients as appear in our results lies in its more diffusive nature.

Finally, we study the way that the current system produces the characteristic ground magnetic signature of the passage of the north-south auroral form. For that, a decomposition of the total horizontal currents $\vec{J}$ into those currents which are caused by divergences inside the analysis area $\left(\vec{J}_{c f}\right)$, those which are caused by
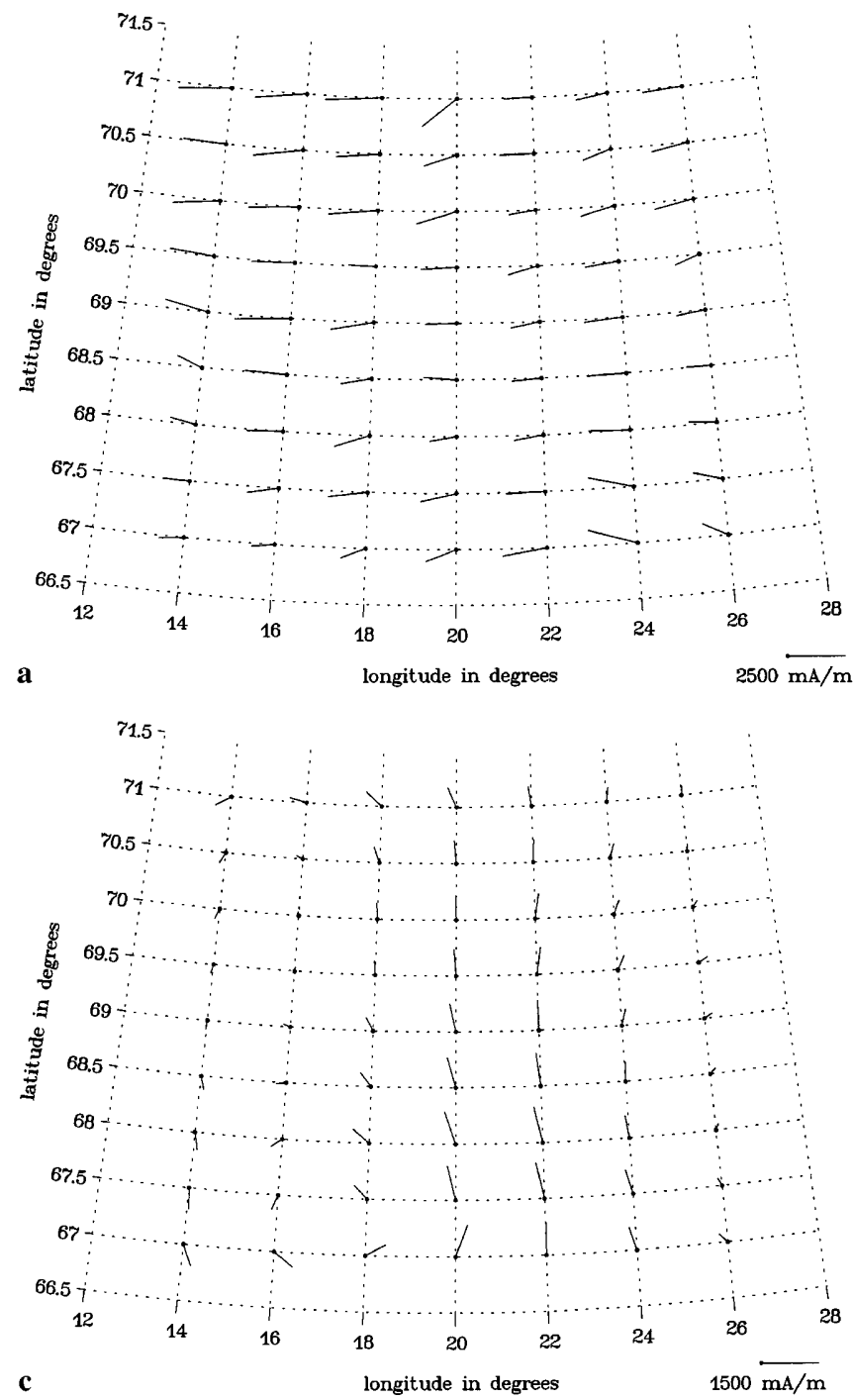

curls inside that area $\left(\vec{J}_{d f}\right)$, and those which are curl- and divergence-free inside our region $\left(\vec{J}_{\text {lap }}\right)$ is carried out (e.g., Amm, 1996). $\vec{J}_{\text {lap }}$ has a potential that satisfies Laplace's equation inside the analysis region.

The result of such an analysis is shown in Fig. 8. Despite of some numerical roughnesses, $\vec{J}_{\text {lap }}$ (Fig. 8a) shows a quite homogeneous westward electrojet with an average magnitude of about $1630 \mathrm{~mA} / \mathrm{m}$. It produces an average southward magnetic disturbance of $530 \mathrm{nT}$ on the ground which corresponds well with the amplitude of the relatively homogeneous westward jet that is present before and immediately after the intensification related to our event. Hence, this current system can be regarded as the 'background system' in front of which the event which is characterized by the $\vec{J}_{c f}$ and $\vec{J}_{d f}$ current systems takes place. However, as far as it is caused by sources outside of the analysis region, the intensification of the westward electrojet during the event is contained in $\vec{J}_{\text {lap }}$, too. $\vec{J}_{c f}$ (Fig. 8b) is dominated by currents flowing southwestward between the regions of strong downward- and upward-flowing FACs in the central north and in the southwest of the area under study. It reaches magnitudes up to $1500 \mathrm{~mA} / \mathrm{m}$. These

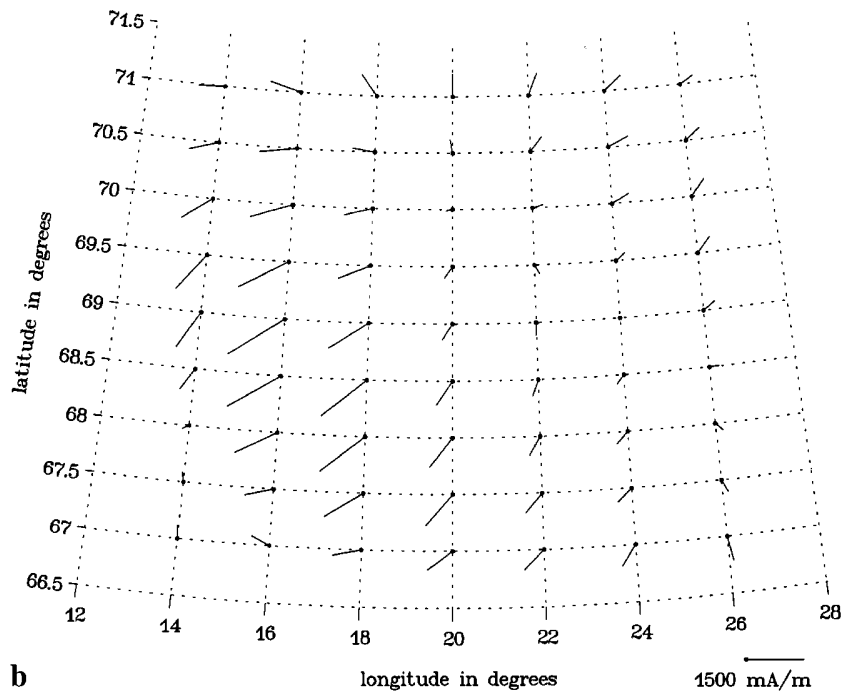

Fig. 8a-c. Decomposition of the total resulting ionospheric current system into its: a curl- and divergence-free part inside the analysis region. b Part that is caused by divergences inside the analysis region. c Part that is caused by curls inside the analysis region 
currents are therefore much stronger than those of $\vec{J}_{d f}$ which only reach magnitudes of about $800 \mathrm{~mA} / \mathrm{m}$ (Fig. 8c). Since $\vec{J}_{c f}$ together with the FAC connected to it does not produce any magnetic field disturbance below the ionosphere (Fukushima, 1976; Amm, 1997), most of the current related to the north-south auroral form is thus magnetically invisible from the ground. On the other hand, in the part current system $\vec{J}_{d f}$, the typical ground magnetic signatures are represented which are added on the westward electrojet by the event (compare Fig. 5a): The north deflection of the by $90^{\circ}$ rotated horizontal magnetic field between 20 and $24^{\circ}$ longitude is clearly visible, and also the curl-like structure in the southwestern part of the analysis area is represented.

\section{Discussion}

The results of our analysis of ground-based data during a passage of a north-south auroral form over northern Scandinavia are, in most respects, compatible with the observations and results of Rostoker et al. (1987) and Liu and Rostoker (1993) on auroral fingers. Their and our observations agree in that the north-south forms appear during an extremely disturbed period more than 10 min after an auroral breakup and the passage of a surge. Since global auroral images are not available for our event, we do not know if the width of the auroral bulge exceeds $10^{\circ}$ latitude as found as a condition for the appearance of such forms by Rostoker et al. (1987), but regarding the intensity of the ground magnetic disturbance, a large bulge evolution seems to be likely. Moreover, the original formation of the surge and of north-south forms occurs eastward of the SMA and STARE fields of view so that we cannot account for a possible time difference between the passing of the structures and their initial evolution. The latitudinal extent of our forms is about $500 \mathrm{~km}$, in agreement with their findings. The longitudinal separation between the two subsequent forms can roughly be estimated as $500 \mathrm{~km}$ which is somewhat larger than the values found by them.

Regarding the scenario that Rostoker et al. (1987) and Liu and Rostoker (1993) proposed for the origin of the auroral fingers, our results show an excellent agreement in that the strongest FACs, colocated with the brightest aurora of the north-south form, are seen at the equatorward edge of the form. According to Liu and Rostoker (1993), this location is a trace of Earthward edge of the electrons' drift path in the central plasma sheet where they are scattered into the loss cone. Moreover, the bipolar FAC geometry that the authors propose in their model is represented in our results, too (compare Fig. 6c). Although they did not precisely specify the expected location of the FACs with respect to the auroral form, it seems reasonable that in our results the upward-flowing FACs are located inside the form since the discrete arc emission should be caused by the precipitating high energy electrons, whereas the downward-flowing FACs are located eastwards and northeastward of it in a region that partly shows diffuse aurora. However, there is one essential difference between the model of Liu and Rostoker (1993) and our observations: since the auroral forms are drifting westwards inside the westward electrojet domain with southward to southwestward electric fields (compare Fig. $5 \mathrm{~b}$ ), the $\vec{E} \times \vec{B}$ drift cannot be the reason of the motion of the form for our event, as it was assumed by the previous authors for their auroral fingers which mainly occurred in the eastward electrojet domain. However, the drift velocity was mainly inferred from the appearance of the forms in the evening sector, and no supporting magnetic or electric field data was shown by Liu and Rostoker (1993).

That this westward drift motion inside the westward electrojet domain is not an uncommon feature of north-south auroral forms is confirmed by the observations of Nakamura et al. (1993) who located their westward-drifting N-S aurora in the same domain using ground magnetic data. Also with respect to all other observational facts, the forms we described agree with those discussed by Nakamura et al. (1993), i.e., their appearance eastward of the surge in a welldeveloped auroral bulge, their latitudinal extent, the possibility of successive forms, and the crescent-like shape of the forms with a tilt to the east, which agree with their easternmost observed N-S auroras. Moreover, the southeastward flow direction corresponding to the southwestward electric field would be compatible to their suggestion of a local two-cell potential associated with the auroral surge (see their Fig. 11). However, the STARE field of view is too small to really prove or disprove the existence of such a potential structure. Using a single station magnetometer record, Nakamura et al. (1993) described the magnetic effect of the N-S aurora as having a similar configuration like that of the Harang discontinuity. This conclusion is not in agreement with our spatial observations.

Finally, we note that nearly the same ground magnetic situation ( 1 min earlier) as analyzed in our study was discussed by Untiedt and Baumjohann (1993) in their review on SMA observations, and classified as one of the most inhomogeneous situations observed by this array. However, the authors did not carry out a combined analysis with radar and ASC data. They proposed that the ground magnetic signature observed is related to an auroral breakup. Our resulting current system in fact shows some similarities to the geometry of the breakup current system as shown in Baumjohann et al. (1981), in that a locally enhanced westward electrojet is diverged by concentrated upward flowing FACs. On the other hand, there are also important differences between their current system and ours. Whereas in the breakup model of Baumjohann et al. (1981), the enhanced westward jet is fed by distant and more distributed downward-flowing FACs, in our case this feeding occurs locally at the northeastern edge of the auroral form (compare Fig. 8b). Moreover, whereas in the breakup model nearly the total electrojet is diverged in the surge, in our case only the additional currents related to the auroral form are diverged, and a 
substantial portion of the jet continues to flow westward of it.

On the other hand, this picture of a localized, additional current wedge is exactly what Chen and Wolf (1993) expected to be the ionospheric current signature of the bursty bulk flows (BBF) in the ionosphere. Our results agree with their predictions in that the downward FAC is located at the eastern side and the upward one at the western side of the wedge. However, besides this longitudinal separation there is also a latitudinal one present in Fig. 6c. The crossstructure size of about $6^{\circ}$ longitude that we estimated from the FAC distribution is slightly smaller, but close to the previous estimate of about 0.5 MLT by Kauristie et al. (1996). From the theory of Chen and Wolf (1993), one would expect a westward-directed electric field in the magnetosphere due to polarization by the inertia drift inside the bubble that contains the BBF. Although the STARE electric field (Fig. 5b) includes some westward vectors, they are not colocated with the auroral structure and do not move together with it.

Since no magnetospheric in situ data is available for our event, we cannot draw a final conclusion about the magnetospheric process that causes the north-south auroral forms. However, the existing similarities of the current system associated with the form studied here and a breakup type, but more localized current system may indicate that these forms can be regarded as periodic, breakup-like but local reintensifications that occur during extremely disturbed periods inside an already developed auroral bulge.

\section{Summary and conclusions}

From the analysis of the ground magnetic disturbance, the ionospheric electric field, and the optical all-sky camera data during a passage of a north-south aligned auroral form on December 2, 1977, we can draw the following conclusions:

1. The auroral form is associated with a strong Hall conductance enhancement, with a maximum value of about $225 \mathrm{~S}$.

2. In contrast to the conductances, the ionospheric electric field is only slightly affected by the passage of the auroral form.

3. Near the equatorward edge of the discrete auroral form, concentrated upward-flowing FACs of magnitudes up to $25 \mathrm{~A} / \mathrm{km}^{2}$ are present. These upward FAC are colocated with the brightest part of the aurora. The current that is diverged by the upward FAC is led into the ionosphere by a sheet of more distributed downward flowing FACs eastward and northeastward of the discrete auroral form. The downward FACs reach a magnitude up to $15 \mathrm{~A} / \mathrm{km}^{2}$, and are located in an area that partly shows diffuse aurora.

4. Most of the three-dimensional ionospheric current system that is associated with the auroral form is curlfree and therefore magnetically invisible below the ionosphere.
5. Our observations and analysis results are generally in good accordance with those of Rostoker et al. (1987) and Liu and Rostoker (1993) on auroral fingers, and with the observations of Nakamura et al. (1993) on N-S aurora. An essential difference to the model of Liu and Rostoker (1993) on the origin of auroral fingers is that for our event, the westward-drift motion of the auroral forms cannot be explained by the $\vec{E} \times \vec{B}$ drift. Furthermore, we cannot support the conclusion of Nakamura et al. (1993) that the magnetic effect of N-S auroras has a similar configuration than that of the Harang discontinuity. Our resulting current system also fits well to the predictions of the ionospheric manifestation of bursty bulk flows by Chen and Wolf (1993). However, the predicted westward magnetospheric electric field associated with the BBF which would be expected to map in the ionosphere in their model is not visible in the STARE measurements.

Acknowledgements. We would like to thank K.H. Glaßmeier (Braunschweig) and J. Untiedt (Münster) for valuable comments and encouragement during this work. We are grateful to V. Sergeev (St. Petersburg) and K. Kauristie (Helsinki) for their comments on the manuscript. The STARE data presented is courtesy of E. Nielsen (Katlenburg-Lindau) whose support is gratefully acknowledged. The work of O.A. was partly supported by a grant of the Deutsche Forschungsgemeinschaft (DFG), and partly by a DAAD fellowship HSP III, financed by the German Federal Ministry for Education and Science.

The Editor-in-chief thanks R. Nakamura and V. Sergeev for their help in evaluating this paper.

\section{References}

Aikio, A. T., and K. U. Kaila, A substorm observed by EISCAT and other ground-based instruments - evidence for near Earth substorm initiation, J. Atmos. Terr. Phys., 58, 5, 1996.

Akasofu, S.-I., J. Kisabeth, B.-H. Ahn, and G. J. Romick, The $S_{q}^{p}$ magnetic variation, equivalent current, and field-aligned current distribution obtained from the IMS Alaska meridian chain of magnetometers, J. Geophys. Res., 85, 2085, 1980.

Amm, O., Direct determination of the local ionospheric Hall conductance distribution from two-dimensional electric and magnetic field data: application of the method using models of typical ionospheric electrodynamic situations, J. Geophys. Res., 100, 21 473, 1995.

Amm, O., Improved electrodynamic modeling of an omega band and analysis of its current system, J. Geophys. Res., 101, 2677, 1996.

Amm, O., Ionospheric elementary current systems in spherical coordinates and their application, J. Geomag. Geoelectr., 49, 947, 1997.

Amm, O., Method of characteristics in spherical geometry applied to a Harang discontinuity situation, Ann. Geophysicae, 16, 413, 1998.

André, D., and W. Baumjohann, Joint two-dimensional observations of ground magnetic and ionospheric electric fields associated with auroral currents. 5. Current system associated with eastward drifting omega bands, J. Geophys., 50, 194, 1982.

Angelopoulos, V., T. D. Phan, D. E. Larson, F. S. Mozer, R. P. Lin, K. Tsuruda, H. Hayakawa, T. Mukai, S. Kokubun, T. Yamamoto, D. J. Williams, R. W. McEntire, R. P. Lepping, G. K. Parks, M. Brittnacher, G. Germany, J. Spann, H. J. Singer, and K. Yumoto, Magnetotail flow bursts: association to global magnetospheric circulation, relationship to ionospheric activity and direct evidence for localization, Geophys. Res. Lett., 24, 2271, 1997. 
Baumjohann, W., R. J. Pellinen, H. J. Opgenoorth, and E. Nielsen, Joint two-dimensional observations of ground magnetic and ionospheric electric field associated with auroral zone currents: current system associated with local auroral break-ups, Planet. Space Sci., 29, 431, 1981.

Bythrow, P. F., and T. A. Potemra, Birkeland currents and energetic particles associated with optical auroral signatures of a westward traveling surge, J. Geophys. Res., 92, 8681, 1987.

Chen, C. X. and R. A. Wolf, Interpretation of high-speed flows in the plasma sheet, J. Geophys. Res., 98, 21 409, 1993.

Elphinstone, R. D., J. S. Murphree, and L. L. Cogger, What is a global auroral substorm?, Rev. Geophys., 34, 169, 1996.

Fujii, R., R. A. Hoffman, P. C. Anderson, J. D. Craven, M. Sugiura, L. A. Frank, and N. Maynard, Electrodynamic parameters in the nighttime sector during auroral substorms, J. Geophys. Res., 99, 6093-6112, 1994

Fukushima, N., Generalized theorem for no ground magnetic effect of vertical currents connected with Pedersen currents in the uniform-conductivity ionosphere, Rep. Ionos. Space Res. Jpn., 30, 35, 1976.

Greenwald, R. A., W. Weiss, E. Nielsen, and N. R. Thomson, STARE: a new radar backscatter experiment in northern Scandinavia, Radio Sci., 13, 1021, 1978.

Haldoupis, C., E. Nielsen, and K. Schlegel, Dependence of radar auroral scattering cross section on the ambient electron density and the destabilizing electric field, Ann. Geophysicae, 8, 195, 1990.

Henderson, M. G., G. D. Reeves, and J. S. Murphree, Are northsouth aligned auroral structures an ionospheric manifestation of bursty bulk flows?, Geophys. Res. Lett., 25, 3737, 1998.

Hoffman, R. A., R. Fujii, and M. Sugiura, Characteristics of the field-aligned current system in the nighttime sector during auroral substorms, J. Geophys. Res., 99, 21 303, 1994.

Ijima, T., and T. A. Potemra, Large-scale characteristics of fieldaligned currents at northern high latitudes observed by Triad, J. Geophys. Res., 83, 2165, 1978.

Inhester, B., W. Baumjohann, R. A. Greenwald, and E. Nielsen, Joint two-dimensional observations of ground magnetic and ionospheric electric fields associated with auroral zone currents. 3. Auroral zone currents during the passage of a westward travelling surge, J. Geophys., 49, 155, 1981.

Inhester, B., J. Untiedt, M. Segatz, and M. Kürschner, Direct determination of the local ionospheric Hall conductance distribution from two-dimensional electric and magnetic field data, J. Geophys. Res., 97, 4073, 1992.

Kamide, Y., B.-H. Ahn, S.-I. Akasofu, W. Baumjohann, E. FriisChristensen, H. W. Kroehl, H. Maurer, A. D. Richmond, G. Rostoker, R. W. Spiro, J. K. Walker, and A. N. Zaitzev, Global distribution of ionospheric and field-aligned currents during substorms as determined from six IMS meridian chains of magnetometers: initial results, J. Geophys. Res., 87, 8228, 1982.

Kamide, Y., Y. Ishihara, T. L. Killeen, J. D. Craven, and L. A. Frank, Combining electric field and aurora observations from DE 1 and 2 with ground magnetometer records to estimate ionospheric electromagnetic quantities, J. Geophys. Res., 94, 6723,1989

Kauristie, K., V. A. Sergeev, T. I. Pulkkinen, R. J. Pellinen, V. Angelopoulos, and W. Baumjohann, Study on the ionospheric signatures of the plasma sheet bubbles, Proc. Third Int. Conf. on Substorms (ICS-3), Versailles, France, 12-17 May, 1996.

Kirkwood, S., H. J. Opgenoorth, and J. S. Murphree, Ionospheric conductivities, electric fields and currents associated with auroral substorms measured by the EISCAT radar, Planet. Space Sci., 36, 1359, 1988.

Kunkel, T., W. Baumjohann, J. Untiedt, and R. A. Greenwald, Electric fields and currents at the Harang discontinuity: a case study, J. Geophys., 59, 73, 1986.

Küppers, F., J. Untiedt, W. Baumjohann, K. Lange, and A. G. Jones, A two-dimensional magnetometer array for ground-based observations of auroral zone electric currents during the International Magnetospheric Study (IMS), J. Geophys., 46, 429, 1979.

Lester, M., J. A. Davies, and T. S. Virdi, High-latitude Hall and Pedersen conductances during substorm activity in the SUNDIAL-ATLAS campaign, J. Geophys. Res., 101, $26719,1996$.

Liu, W. W., and G. Rostoker, On the origin of auroral fingers, J. Geophys. Res., 98, 17401, 1993.

Lopez, R. E., H. E. Spence, and C.-I. Meng, DMSP F7 observations of a substorm field-aligned current, J. Geophys. Res., 96, 19409, 1991.

Nakamura, R., T. Oguti, T. Yamamoto, and S. Kokubun, Equatorward and poleward expansion of the auroras during auroral substorms, J. Geophys. Res., 98, 5743, 1993.

Opgenoorth, H. J., R. J. Pellinen, H. Maurer, F. Küppers, W. J. Heikkila, K. U. Kaila, and P. Tanskanen, Ground-based observations of an onset of localized field-aligned currents during auroral breakup around magnetic midnight, J. Geophys., 48, 101, 1980.

Opgenoorth, H. J., R. J. Pellinen, W. Baumjohann, E. Nielsen, G. Marklund, and L. Eliasson, Three-dimensional current flow and particle precipitation in a westward traveling surge (observed during the Barium-GEOS rocket experiment), J. Geophys. Res., 88, 3138, 1983a.

Opgenoorth, H. J., J. Oksman, K. U. Kaila, E. Nielsen, and W. Baumjohann, Characteristics of eastward drifting omega bands in the morning sector of the auroral oval, J. Geophys. Res., 88, 9171, 1983b.

Robinson, R. M., and R. R. Vondrak, Electrodynamic properties of auroral surges, J. Geophys. Res., 95, 7819, 1990.

Robinson, R. M., F. Rich, and R. R. Vondrak, Chatanika radar and S3-2 measurements of auroral zone electrodynamics in the midnight sector, J. Geophys. Res., 90, 8487, 1975.

Rostoker, G., A. T. Y. Lui, C. D. Anger, and J. S. Murphree, Northsouth structure in the midnight sector auroras as viewed by the Viking imager, Geophys. Res. Lett., 14, 407, 1987.

Schlegel, K., Auroral zone E region conductivities during solar minimum derived from EISCAT data, Ann Geophysicae, 6, 129, 1988.

Sergeev, V. A., V. Angelopoulos, C. A. Cattell, and C. T. Russell, Detection of localized plasma bubbles in the plasma sheet, J. Geophys. Res., 101, $10817,1996$.

Sergeev, V. A., K. Liou, C.-I. Meng, P. T. Newell, M. Brittnacher, G. Parks, and G. D. Reeves, Development of auroral streamers in association with localized impulsive injections to the inner magnetotail, Geophys. Res. Lett., 26, 417, 1999.

Untiedt, J., and W. Baumjohann, Studies of polar current systems using the IMS Scandinavian magnetometer array, Space Sci. Rev., 63, 245, 1993. 